\title{
Is Joining a Business Incubator or Accelerator Always a Good Thing?
}

\author{
Kristina Lukosiute, Søren Jensen, and Stoyan Tanev
}

\author{
"It is a good thing to learn caution from") \\ the misfortunes of others. \\ Publilius Syrus (85-43 BC) \\ Writer
}

\begin{abstract}
Business incubators and accelerators are often hailed as essential tools for fostering growth in startups. However, not only do entrepreneurs often face the question of which incubator or accelerator to join, we suggest that they should also question whether or not to join one at all. Is joining a business incubator or accelerator always a good thing? In this article, we investigate some of the negative outcomes entrepreneurs can experience when engaging with an incubator or accelerator. We apply a cross-case analysis of empirical observations from qualitative interviews with Danish and Canadian entrepreneurs to arrive at a set of recommendations that entrepreneurs should keep in mind when considering such an engagement. These points are further qualified based on informal interviews with four serial entrepreneurs.
\end{abstract}

\section{Introduction}

The concept of business incubation remains topical and yet it is now more than fifty years old (AlMubaraki \& Busler, 2010). The spread of business incubation practices across the world has opened a new dimension in management theory and practice. Indeed, over time, the need to manage incubation programs in a way that helps the formation and growth of startups has become increasingly important (ECA, 2014).

Today's typical entrepreneurial ecosystems accommodate multiple incubators, which usually complement each other in terms of the services they offer. Such multiplicity provides an opportunity for earlystage startups to maximize their chances for success by shaping specific incubation strategies that combine multiple complementary incubation environments (Jakobsen et al., 2017). According to Al-Mubaraki \& Busler (2010), the most frequently provided services are marketing assistance, help with everyday business operations, linkages to strategic partners, networking activities, Internet access, help with accounting, and linkages to angel or venture capital investors.
Understandably, existing research focusing on business incubation emphasizes the potential benefits for startups, the characteristics of successful incubators, and the factors that could enhance the chances for success of both startups and incubation environments. There is, however, another side of the coin because, "while generally beneficial to new entrepreneurial start-ups, there are some disadvantages associated with incubator units but these are rarely recognized or discussed within the extant literature" (Barrow, 2001: 362; Mcadam \& Marlow, 2007). Unfortunately, there is little research focusing on some of the potential drawbacks or disadvantages of participating in incubation programs. The objective of the present article is to suggest an alternative exploratory perspective by summarizing the results of a preliminary empirical study focusing on identifying some of the potential disadvantages of joining and completing incubation or acceleration programs.

The content of the article is organized as follows. The next section summarizes the key insights from the literature. It reviews some of the definitions of incubators and accelerators and discusses the sometimes-confusing overlaps between them. In addition, some of the key 


\section{Is Joining a Business Incubator or Accelerator Always a Good Thing?}

Kristina Lukosiute, Søren Jensen, and Stoyan Tanev

risks of joining an incubator are discussed. The Research methodology section describes the research steps, the sources of empirical data, and the type of data analysis to be performed. The Results section summarizes some of the negative experiences of entrepreneurs who have been part of business incubation programs and provides some reflections about the differences in these experiences in incubator-like and accelerator-like environments. Finally, the Conclusion provides some final reflections and summarizes some of the most typical downsides of being part of an incubator or accelerator.

\section{Key Insights from the Literature}

According to Gunter (2012), startups tend to be the most rapid job creators. Either startups move up by rapidly expanding their innovation to become economically successful, or they rapidly go out of business. Very often, startups develop radically innovative products and, eventually, disrupt existing markets. However, startups who seek to do things differently face several challenges and uncertainties associated with the shaping of a viable business model, reaching out to early buyers, setting up durable partnerships and sustainable operations, etc. To deal with these challenges and uncertainties, startups usually benefit from all available resources including existing regional and national business incubation programs.

\section{Incubation vs accelerators}

In order to establish a successful business, entrepreneurs are often looking for business programs that could help the growth of their business. In fact, incubators and accelerators are meant to boost the successful development of newly created firms by increasing the likelihood of their survival and growth. Incubators and accelerators should enable a smooth start and future growth for startups. However, many concepts of incubators and accelerators have been put forward, which sometimes confuses both scholars and practitioners.

The original concept of an incubator has changed since the first private incubator was established in New York in 1959 (Hausberg \& Korreck, 2018). Since then, many different forms of entrepreneurship support have emerged, one of which is the accelerator. The first seed accelerator was Y Combinator in 2005, which was followed by TechStars in 2006. Many others have followed their lead, but Y Combinator and TechStars remain two of the top accelerators in the world today.
Such programs are now commonplace, but there is still confusion regarding the terms incubator and accelerator. For example, many startup programs that describe themselves using the same term do not share common characteristics (Dee et al., 2015).

Thus, in order to make a distinction between these two terms, it is necessary to answer the following questions:

-What does an incubator or accelerator offer?

-Who is an incubator or accelerator targeting?

\section{Characteristics of an incubator}

The goal of incubators can differ depending on the type. Hausberg and Korreck (2018) define business incubators as "organizations that support the establishment and growth of new businesses with tangible (e.g. space, shared equipment and administrative services) and intangible (e.g. knowledge, network access) resources during a flexible period and are funded by a sponsor (e.g. government or corporation) and/or fund themselves taking rent (or less frequently equity) from incubatees." Certainly, the most typical goal of an incubator is to foster entrepreneurship and develop new firms, but different incubators can have different priorities. They target ventures that are in their early development stages, so the term incubator should not be used interchangeably with the terms science park or technology park, which are generally designed to support more mature firms (Hausberg \& Korreck, 2018). According to Irshad (2014), incubators can be classified based on objectives, formation, types, industry, source of finance, location, and the specific combination of all of these. For instance, the objective of a non-profit incubator is to create new jobs and increase tax bases. Typically, non-profit incubators are operated by government institutions. For-profit incubators are focusing on return on investment and profitability. University-based incubators can be situated somewhere between non-profit and for-profit (Hausberg \& Korreck, 2018).

\section{Characteristics of an accelerator}

As described above, in 2005, a new institutional form of business incubation emerged: the accelerator. Accelerators incorporate some of the characteristics of incubators and business angels (Bueren, 2016). They adopt a distinctive incubation model with a unique way of structuring incubation, growth, and investment initiatives. Interestingly, the founder of the Y Combinator, Paul Graham, called the organization a "seed-stage investment firm" instead of accelerator (Bliemel et al., 2016). 


\title{
Is Joining a Business Incubator or Accelerator Always a Good Thing?
}

\author{
Kristina Lukosiute, Søren Jensen, and Stoyan Tanev
}

There is, therefore, a distinction between the classic business incubator and a typical accelerator. "Accelerators usually are fixed-term, cohort-based programs providing education, monitoring, and mentoring to start-up teams (usually not single entrepreneurs) and connecting them with experienced entrepreneurs, venture capitalists, angel investors and corporate executives and preparing them for public pitch events in which graduates pitch to potential investors" (Hausberg \& Korreck, 2018).

The risks associated with selecting and joining an incubator or accelerator

A critical assessment of the effectiveness of an incubator or accelerator can guide entrepreneurs to make the right decisions about engaging with specific business support programs. Many entrepreneurs are novices who lack competencies, working capital, and potential for funding. Entrepreneurs make decisions based on what they perceive, and startups often want to be accepted into a well-established program without considering if it is the right program to be in. According to Bliemel and co-authors (2016), entrepreneurs usually apply to join an accelerator because they need seed funding, incubation services, and partnership networks. They emphasized that, for example, when entrepreneurs are only seeking mentorship, an accelerator program could be detrimental to them since there are many risks associated with an accelerator. Miller \& Bound (2011) articulated several criticisms of accelerator models:

- After graduating an accelerator, startups are still fragile and in need of support.

- The equity taken by accelerators becomes problematic for further funding. Startups fear "Rich guys launching 'startup accelerators' so they can rip off new start-up founders” (Miller \& Bound, 2011).

- Because of the increasing number of accelerators and their tendency to invest in early-stage firms, B-grade companies will not receive investment.

- "If accelerators continue to grow and start producing thousands of small companies, we can expect to see a bottleneck developing and in the event of a crash in confidence in the sector" (Miller \& Bound, 2011).

- Accelerators will become "startup schools" who will encourage learning through educational returns rather than building real businesses.
- Accelerators build small companies that do not have quite global ambitions. These are companies that are building something that will become a feature of a larger service, rather than aiming to become a large company in its own right.

- Accelerators are making entrepreneurship so accessible that they start draining talent from larger technology firms.

$\mathrm{Yu}$ (2015) argues that founders with promising ideas avoid joining accelerators and instead choose different ways of progressing. For most of them, an accelerator without a well-established value ecosystem and network is worthless. On the other hand, the best startup exit for an accelerator or for-profit incubator comes when the startup is acquired. In this sense, an accelerator is just another type of incubator, whose goal is to increase the startups' survival chances (Hausberg \& Korreck, 2018). But there remains a lot of definitional uncertainty. As Mian and co-authors (2016) emphasized, the definition of accelerators cannot be generalized due to idiosyncrasies in their relations to political, economic, social, and geographic conditions.

The summary of the risks associated with the possibility of startups joining business incubation programs demonstrates the need for more systematic studies focusing on the potential downsides of business incubation practices. The next section describes the methodology adopted to answer our initial research question, starting with the hypothesis that it is not always beneficial for new ventures to join business incubation programs.

\section{Research Methodology}

For this study, we adopted an explorative qualitative research approach using multiple semi-structured interviews with startup founders, complemented by informal discussions with serial entrepreneurs. We designed the questions around issues related to some of the negative experiences of going through specific incubation/acceleration programs and how such experiences affected the future of specific ventures. The interviewees were the founders of eight startups: four in Denmark (two active and two partly active) and four in Canada (three active and one inactive). We believe that the mixture of active (still operating), partly active (still operating but with declining activities) and inactive (non-operating) companies would provide a broader spectrum of opinions and experiences relevant to our 


\section{Is Joining a Business Incubator or Accelerator Always a Good Thing?}

Kristina Lukosiute, Søren Jensen, and Stoyan Tanev

study. Table 1 provides an overview of the eight startups featured in the in-depth interviews with their founders. Each interview was recorded, transcribed, and coded to help identify key observations. The observations were then cross-analyzed to identify and prioritize the emerging common issues that could be used as a basis for the formulation of practical insights.

The in-depth interviews with the startups' founders were complemented with insights from informal discussions with additional four serial entrepreneurs (SE1, SE2, SE3, and SE4). SE1, SE2, and SE3 are Canadian serial entrepreneurs working within the digital marketing/cryptocurrency, SaaS, and computer science industries, respectively. SE4 is a Lithuanian serial entrepreneur working within the IT sector.

\section{Results}

As Eisenhardt (1989) has emphasized, there are many divergent ways to look at qualitative data. In this study, we chose to examine the similarities between codified key insights. Then similar codified key insights were assigned to a single coding category. The codes were created by using both pre-set codes and emergent codes. Pre-set codes derived from existing research articles focusing on various aspects of business incubation programs and were incorporated into the interview guides, while emergent codes emerged from analyzing the data. The analysis identified seven categories, and based on insights from the interviews, a cross-case analysis was performed. The categories and key insights of the cross-case analysis can be found in Table 2, and they are discussed in greater detail in the subsections that follow.

In our analysis, we do not explicitly distinguish between incubators and accelerators and used the more general term "business incubation program". We did this for two main reasons. First, the existing definitions sometimes overlap in some of the characteristics of the incubation programs, which makes it difficult to apply the terms in practice in a clear-cut fashion. Second, the incubation program managers themselves sometimes use the terms incubator and accelerator in a relatively loose sense based on personal preferences, previous experience, and the established language in their communities. We will focus therefore on the negative experiences of entrepreneurs who have been part of business incubation programs and provide some reflections at the end about the differences between incubator-like and accelerator-like environments.

Admission criteria: Incubation programs did not perform due diligence and assessment to ensure startup quality

Business incubation programs have different approaches to the selection of startup clients. The success or failure of a startup in a business incubation program depends on how qualified the program managers are in selecting the right startups at the right stage. Four out

Table 1. Overview of the eight startups selected for in-depth interviews with their founders

\begin{tabular}{clcc}
\hline Case & Description of Startup / Key Product & Status & Country \\
\hline A & Student-founded startup focusing on designing furniture & Active & Denmark \\
\hline B & Premium-priced product to reduce stress and anxiety & Partly active & Denmark \\
\hline C & Business consultancy in creativity and innovation & Active & Denmark \\
\hline D & Product to make automated production line more efficient & Partly active & Denmark \\
\hline E & A platform for students to find and apply for scholarships & Active & Canada \\
\hline F & Synthetic cannabidiols for the treatment of pediatric epilepsy & Active & Canada \\
\hline G & $\begin{array}{l}\text { Engineering service provider working towards building a portfolio of intellectual } \\
\text { property related to the control and operation of robotic assets in space }\end{array}$ & Active & Canada \\
\hline H & Online booking platform that simplifies access to workspace and recreation facilities & Inactive & Canada
\end{tabular}




\title{
Is Joining a Business Incubator or Accelerator Always a Good Thing?
}

\author{
Kristina Lukosiute, Søren Jensen, and Stoyan Tanev
}

Table 2. Summary of insights from the cross-case analysis related to the negative aspects of incubation/acceleration, as perceived by the founders of startups interviewed in this study

\begin{tabular}{|c|c|c|c|}
\hline Category & Insight & Code & Frequency \\
\hline Admission criteria & $\begin{array}{l}\text { Incubation programs did not perform due diligence and assessment to } \\
\text { ensure startup quality }\end{array}$ & A, B, C, D & $4 / 8$ \\
\hline \multirow[t]{4}{*}{ Services and offerings } & $\begin{array}{l}\text { General workshops, courses, and lectures about entrepreneurship were } \\
\text { not found to be valuable }\end{array}$ & B & $1 / 8$ \\
\hline & Startups received low commitment from program mentors and advisors & $\mathrm{D}, \mathrm{E}, \mathrm{F}, \mathrm{H}$ & $4 / 8$ \\
\hline & $\begin{array}{l}\text { The incubation program did not meet the company's initial } \\
\text { expectations }\end{array}$ & $\mathrm{B}, \mathrm{D}$ & $2 / 8$ \\
\hline & $\begin{array}{l}\text { Tangible services such as access to manufacturing capabilities were not } \\
\text { provided or were limited }\end{array}$ & A, C, F, G & $4 / 8$ \\
\hline \multirow[t]{3}{*}{ Network } & $\begin{array}{l}\text { Startups did not efficiently use the office space provided by the } \\
\text { incubation program }\end{array}$ & $\mathrm{B}, \mathrm{E}, \mathrm{H}$ & $3 / 8$ \\
\hline & $\begin{array}{l}\text { The incubation program's network was not aligned to the startup's } \\
\text { product }\end{array}$ & A, D, F & $3 / 8$ \\
\hline & Startups were unaware of the business incubation program's ecosystem & E, F & $2 / 8$ \\
\hline Financial resources & $\begin{array}{l}\text { Business incubation programs did not provide direct or indirect access } \\
\text { to investment }\end{array}$ & $\mathrm{B}, \mathrm{D}$ & $2 / 8$ \\
\hline Equity & $\begin{array}{l}\text { Equity taken by the business incubation program made startups } \\
\text { unattractive to potential investors }\end{array}$ & $\mathrm{D}$ & $1 / 8$ \\
\hline IP protection & $\begin{array}{l}\text { Participation in a business incubation program put intellectual property } \\
\text { at risk }\end{array}$ & $\mathrm{F}$ & $1 / 8$ \\
\hline Post-incubation & $\begin{array}{l}\text { Following incubation, startups looked to join another business } \\
\text { incubation program or sought business angels }\end{array}$ & A, B, E & $3 / 8$ \\
\hline
\end{tabular}

of the eight startups mentioned that their business incubation programs did not perform formal due diligence because of two main reasons: 1) they were newly established or 2) the program managers simply believed that the product was in line with the program's focus and competencies. None of those four startups received feedback or were evaluated by the program. It could be assumed, therefore, that incubation programs acted in their own self-interest when attracting new tenants and raising public awareness of their programs. This is especially applicable to university-based business incubation programs, which are more supportive and more inclusive in nature. SE4, who was co-founder of an incubation program, pointed out that demo days are only for community, to show that the program is still operating. Overall, entrepreneurs should be conscious that incubation programs are not always necessarily acting in the best interest of startups. Moreover, an incubation program's admission process should be seen as an indicator of how seriously managers are taking a startup into consideration. Without due diligence on by both the programs and the startups, startups are at risk of becoming part of a program that is not necessarily valuable to them.

Services and offerings: General workshops, courses, and lectures about entrepreneurship were not found to be valuable

One out of the eight startups mentioned that general workshops and lectures about entrepreneurship were 


\title{
Is Joining a Business Incubator or Accelerator Always a Good Thing?
}

\author{
Kristina Lukosiute, Søren Jensen, and Stoyan Tanev
}

not found to be valuable. Startup B emphasized that it was a waste of time to participate in general workshops when the company needed financial resources to develop a minimum viable product (MVP). Without a functional prototype, startup B was unable to demonstrate their proof-of-concept. Despite spending one year in a university-based incubation program, startup B has not succeeded in developing a functional prototype. Thus, startups who are involved in the program can spend a lot of time working on secondary tasks, instead of focusing on primary ones. According to SE3, business incubation programs "keep startups busy with stuff which they don't really need to do like presentations, instead of helping them with securing first customers."

\section{Services and offerings: Startups received low commit- ment from program mentors and advisors}

Four out of the eight startups emphasized that they received low commitment from program mentors and advisors. Startup F gave an example in which the lawyer of their incubation program suggested not to file a patent application in China despite the company's plans to expand globally and build a pilot plant in Hong Kong. Startup E has not received any support from mentors and advisors and wished there was someone to keep them accountable. Startup D, as with start-up E, has been left on its own. Startup $\mathrm{H}$ failed to leverage a sound marketing strategy and expected advisors to help them earlier in the process. SE2, who has also passed through a university-based business incubation program, indicated that some of the mentors were professors and a variety of mentors would have been more appropriate. SE4 mentioned that some entrepreneurs do not get appropriate help from incubation programs because that help is untargeted, as service providers are not interested in startup results.

\section{Services and offerings: The incubation program did not meet the company's initial expectations}

Business incubation programs promise startups a variety of services. However, according to SE1, the quality of these services, and even their availability, might be in doubt. Such a situation happened to startup D and startup B. Startup D complained that the program managers promised to help with further product development, but their company never subsequently received such help. Startup B was totally disappointed with their program, as it provided only physical space and general workshops while the company expected to get help with acceleration, mentoring, legal advice, investors, and networking. Startup B was even willing to pay for services if the program was able to provide what they needed. Accordingly, startups should make sure in advance that business incubation programs will provide what they promised and what was expected from them based on the initial formal or informal agreements.

Services and offerings: Tangible services such as access to manufacturing capabilities were not provided or were limited

One of the reasons why startups join a business incubation program is access to office space. However, other tangible services such as manufacturing and prototyping capabilities are no less important. Startup F joined a program because of the potential access to prototyping labs. They emphasized that renting a lab can cost a fortune. Startup F developed a kit to test marijuana oils, but because they did not have access to a workshop, it became impossible to produce the kits. Startup A emphasized that existing manufacturing firms require a continuous production supply and are not interested in signing contracts with startups. In addition, startup A was not allowed to use the resources of the university incubation program for commercial purposes. Thus, it could not achieve a competitive advantage based on early prototyping. Startup C also noticed that startups who have physical products face difficulties in getting into contact with potential manufacturers. Startup G wished that the program facilities had a workshop, where they could test their product.

\section{Network: Startups did not efficiently use the office space provided by the incubation program}

The purpose of startups sharing the same office space is the opportunity to build relationships with peers. Startup $\mathrm{H}$ emphasized that sharing an environment with people who are going through the same challenges is very valuable. In fact, startup $H$ established a partnership with another startup that was part of their incubation space - something that would not have been possible if they were not using the same physical space. In addition, startup $\mathrm{H}$ mentioned that, at a certain moment of time, the attendance of startup teams in the office space dropped down significantly, which reduced opportunities for collaboration. Startup B felt frustrated that only 2 or 3 startups out of 15 used the office space on a regular basis. Startup E also noticed that attendance of the startup teams diminished over time. After all, the entrepreneurs themselves started to question if there was a difference between using the incubation office space and working at home.

\section{Network: The incubation program's network was not aligned to the startup's product}

As was emphasized in the literature review, incubation programs provide more generic network resources and 


\title{
Is Joining a Business Incubator or Accelerator Always a Good Thing?
}

\author{
Kristina Lukosiute, Søren Jensen, and Stoyan Tanev
}

offer less idiosyncratic network resources, because it is not practical for a program to even try to address each potential startup's every need. Accordingly, three out of the eight startups who joined a more general incubation program (i.e., with no specific sector of focus) stated that the program cannot help them with connections to strategic partners. Startup F needed access to pharmaceutical and chemical manufacturing industries in order to secure access to a valuable supply chain. Since the program network was not in line with their product, the startup had to build its own network. Startup A needed access to manufacturers and distributors in order to start commercial production. Since the incubation program did not provide the necessary connections, startup A considered finding a business angel with the right competencies and knowledge in the field. Startup D needed access to the automation industry in order to test a product and meet potential customers. However, the incubation program was more focused on the healthcare industry than automation. Startup D spent 10 months in an incubation space without any luck establishing the necessary partnerships in order to commercialize the product or even test it at a customer's site. According to Mas-Verdú and co-authors (2015), business incubation environments are insufficient on their own and have to be aligned with other businesses characteristics such as technology, size (number of employees), and sector. In general, generic network resources are valuable only for those startups that do not know how to pursue their business idea. Startups who are looking for strategic partners in order to commercialize their product should join sector-based incubation programs.

\section{Network: Startups were unaware of the business incub- ation program's ecosystem}

Sa and co-authors (2012) stressed that entrepreneurs cannot fully benefit from an incubator's resources when those resources are not well coordinated. Two out of the eight startups mentioned that they were unaware of the ecosystem of the business incubation program. Both startups were part of a university-based program. Startup F found out about some of the existing resources, but only by accident. Meanwhile, startup E mentioned that the services provided by the program were not very well advertised. Startups who were unaware of the existing program resources started looking for resources outside of the incubation environment, which is a time-consuming process. Therefore, business incubation programs must make sure that their startups are informed about available resources.

\section{Financial resources: Business incubation programs did} not provide direct or indirect access to investment

To cross the valley of death, startups can use the resources of the business incubation environment to secure initial funding. Startup D had a proof-of-concept and was ready for investors. However, none of the investors from the incubation program's network were willing to invest in it. After a few unsuccessful attempts to find investors, the incubation program stopped trying to help with investment search despite earlier assurances from the incubation program managers that startup D would receive funding from their investor network. Startup B was not ready for initial funding but needed seed money in order to finalize their prototype. The rest of the interviewed startups either were not ready for investors or they succeeded in attracting investors by themselves. According to Rijnsoever and coauthors (2016), non-incubated startups who have access to the same investors raise as much funding as incubated startups. Accordingly, being part of a business incubation space does not necessarily mean that a startup will receive funding or be connected to potential investors.

Equity: Equity taken by the business incubation program made startups unattractive to potential investors

Different business incubation spaces operate under different business models. Most of them are looking to promote regional growth, while others are focusing on generating financial returns from equity. Startup D joined an incubation space with high hopes of securing investors, potential customers, and product development in exchange for $38 \%$ equity. The incubation program did not help with product development and customers, but it was ready to charge the startup for other services. Startup D did not use any of the services, because the services were not good enough and were not worth paying for. As it appears, the incubation program adopted a for-profit property development model to charge a fee for services offered. However, the startup did not receive any investment through the program. The program only provided office space and connections to investors. In fact, most of the startups in this program received an investment from other institutions operating in the region and the program managers only advised startup D to approach them directly. On the other hand, the funding institutions were running government-initiated incubation programs that filled the gap of financing when nobody wants to invest in earlystage startups. Those government-initiated programs seemed to provide better, free, or much cheaper, mentoring and consultancy for startups. 


\title{
Is Joining a Business Incubator or Accelerator Always a Good Thing?
}

\author{
Kristina Lukosiute, Søren Jensen, and Stoyan Tanev
}

On the other hand, SE3, who was involved in a government-led incubation program, mentioned that the program focused on taking startups at the point where they are ready for investment. SE3's company never needed an investment because they used bootstrapping. According to SE3, the best exit strategy for incubation programs is when their client startups are acquired.

\section{IP Protection: Participation in a business incubation program puts intellectual property at risk}

Participating in an incubation program can put a startup's intellectual property (IP) at risk because multiple entrepreneurs share office space, workshops, laboratories, and mentors. Startup F emphasized that their product and IP can be very easily exposed to third parties as everyone can access the incubation program lab and office facility. Since most incubation programs do not provide legal services and obtaining a patent is expensive, startups bear the risk of IP exposure. On the other hand, it is typically not the responsibility of the incubation program to protect their startup's intellectual property.

\section{Post-incubation: Following incubation, startups looked to join another business incubation program or sought business angels}

Usually, startups go through several incubation programs to build or acquire necessary resources for their businesses. After spending some time at a universitybased early stage incubation program in Ontario, Canada, startup E applied to join another one, because they were looking for more dedicated hands-on mentoring and business support focusing on growth. Startup B, in Denmark, applied to join a university-based incubator but the application was rejected because the program was for students only. As a result, startup B applied to a regional investment agency in order to receive funding. Startup A is considering finding a business angel who will help with distributors and manufacturers. Accordingly, when an incubation program provides idiosyncratic resources or limits access to complementary assets, startups start to look for those resources in other programs or try to find business angels. Therefore, startups should understand that graduation from an incubation program does not necessarily mean that they will be ready for the market or able to grow and scale-up.

\section{Conclusion}

This section summarizes the key insights gathered from our research and analysis. In addition, it focuses on results that can be used to improve an entrepreneur's understanding of incubation programs. The analysis of the empirical observations resulted in the articulation of the following downsides of being part of a specific incubation program.

- Equity dilution can lead a startup to bankruptcy. Startups who have diluted too much equity to an incubator or accelerator will struggle to convince investors to invest in them later. Every time a startup issues new shares, the existing shareholder's equity decreases.

- Startups can face low commitment from incubation program stakeholders such as business mentors, advisors, and external partners. External service providers are usually not interested in startups' results.

- Putting IP at risk. Startups who join an incubation program are risking exposing their product or idea to third parties that have similar access to the incubation facilities. Half of the interviewed incubation programs do not provide legal advice nor IP consultancy.

- Young and inexperienced incubation programs do not do enough due diligence since, most often, their main goal is to fill spots and enhance their regional reputation.

- Startups can be unaware of the business and innovation ecosystem of the incubation program. Some programs do not do a good job in advertising the expertise and knowledge of their networks.

- General workshops, lectures, and courses provided by incubation programs are time-consuming and not necessarily useful. Startups spend a lot of time working on secondary tasks instead of focusing on primary ones. For instance, an interviewed startup spent 12 months in an incubator and was not been able to build a functional prototype during that time period.

- Incubation program networks may not align with a startup's product. The majority of the incubation programs provided only general network resources.

- Incubation programs do not usually provide seed money, investment, or connections to investors. In fact, being part of an incubation program does not guarantee any investment.

- The collaboration opportunities significantly decrease when an incubation space is underutilized and only a few startups use the office facility. 


\title{
Is Joining a Business Incubator or Accelerator Always a Good Thing?
}

\author{
Kristina Lukosiute, Søren Jensen, and Stoyan Tanev
}

- Prior to joining an incubator or accelerator, startups should consider whether or not they would need specialized facilities/equipment. Most of the interviewed founders participated in incubation programs that did not have specialized facilities/equipment.

- Startups may go through multiple incubation programs to acquire or build necessary resources. Therefore, startups who have not received necessary help or resources in a specific incubation program consider joining other programs or finding business angels with the right competencies for the startup's context.

Finally, consider the differences between incubator-like and accelerator-like programs in the way they refer to startups that have used multiple incubation programs. The general tendency for startups using multiple incubation programs is to move from early-stage incubation to more dedicated acceleration programs. As a rule, university-based programs are focusing on early incubation offering young entrepreneurs the opportunity the experience of being an entrepreneur. In this sense, we should be careful when comparing the performance of incubators because their missions could be quite different. On the other hand, acceleration programs tend to focus on growth objectives and stronger investment exposure and opportunities. Even though early-stage incubators also claim to offer funding-related networking opportunities, their focus seems to be on the quality of

the entrepreneurial experience and the validation of the viability of the emerging business opportunities.

In conclusion, it is not always a good thing for a startup to join an incubator or accelerator. Or, rather, there are multiple aspects of business incubation practices that could affect negatively early-stage companies, and founders of new ventures should be very careful when selecting a specific incubation program. The answer, of course, cannot be considered in black and white terms since the focus of the selection process should be on the interference of the multiple factors that could potentially affect the future of a startup in terms of operations, market potential, external funding, etc.

We believe that the analysis provided here will enhance the awareness of both researchers and practitioners about the potential negative impact of improperly selected incubation programs. It should enable executive managers of existing incubation programs to refine their startup selection process and better articulate the value propositions of their programs. At the same time, we should point out that our study is based on a limited number of cases. Future studies should build a broader empirical base by selecting a larger number of startups and more sophisticated methodologies, taking into account the distinction between the incubation programs, the stage, and the strategic goals of the new ventures. 


\section{Is Joining a Business Incubator or Accelerator Always a Good Thing?}

\section{Kristina Lukosiute, Søren Jensen, and Stoyan Tanev}

\section{About the Authors}

Kristina Lukosiute is a business and innovation practitioner helping new companies articulate viable business models and competitive marketing strategies. She holds an MSc in Engineering Product Development and Innovation from the University of Southern Denmark, Odense, Denmark, and the present article is based on her thesis work.

Søren Jensen is an Associate Professor in the Faculty of Engineering at the University of Southern Denmark. Previously, he worked in a seed-financing company analyzing technology business ideas. As an investment analyst, his special interests lay within intellectual property and technology assessment. He now teaches intellectual property and entrepreneurial business understanding.

Stoyan Tanev, PhD, MSc, MEng, MA, is Associate Professor of Technology Entrepreneurship and Innovation Management associated with the Technology Innovation Management (TIM) Program and Sprott School of Business at Carleton University in Ottawa, Canada. Before re-joining Carleton University, Dr. Tanev was part of the Innovation and Design Engineering Section in the Faculty of Engineering at the University of Southern Denmark (SDU), Odense, Denmark. Dr. Tanev has a multidisciplinary background including an MSc in Physics (Sofia University, Bulgaria), a PhD in Physics (1995, University Pierre and Marie Curie, Paris, France, co-awarded by Sofia University, Bulgaria), an MEng in Technology Management (2005, Carleton University, Ottawa, Canada), an MA in Orthodox Theology (2009, University of Sherbrooke, Montreal Campus, QC, Canada), and a PhD in Theology (2012, Sofia University, Bulgaria). Dr. Tanev's current research interests are in the fields of technology entrepreneurship and innovation management, design principles and growth modes of global technology startups, business analytics, and data/text mining. He also has an interest in interdisciplinary epistemological issues on the interface of philosophy of religion, Orthodox theology, and the natural and social sciences.

\section{References}

Al-Mubaraki, H. M., \& Busler, M. 2010. Business Incubators: Findings from a Worldwide Survey, and Guidance for the GCC States. Global Business Review, 11(1): 1-20. https://doi.org/10.1177/097215090901100101

Barrow, C. 2001. Incubators: A Realist's Guide to the World's Business Accelerators. Chichester, UK: Wiley.

Bliemel, M., Flores, R., De Klerk, S., Miles, M., Costas, B., \& Monteiro, P. 2016. The Role and Performance of Accelerators in the Australian Startup Ecosystem. Final report for the Department of Industry, Innovation \& Science. Sydney, Australia: UNSW Business School. https://archive.industry.gov.au/industry/OtherReportsandStudies /Documents/The-role-and-performance-of-accelerators-in-theAustralian-startup-ecosystem.pdf

Bueren, K. P. 2016. Accelerators, Startup Performance, and Crises. Master of Science in Management Studies Thesis. Cambridge, MA: MIT Sloan School of Management, Massachusetts Institute of Technology.

https://dspace.mit.edu/handle/1721.1/104509

Dee, N., Gill, D., Weinberg, C., \& McTavish, S. 2015. Startup Support Programmes: What's The Difference? Nesta Innovation Foundation Report. London: Nesta.

https://www.nesta.org.uk/report/startup-support-programmeswhats-the-difference/

ECA. 2014. Has the ERDF Successfully Supported the Development of Business Incubators? Luxembourg: European Court of Auditors (ECA).

https://ebn.eu/system/download.php?f=/downloads/Special_Rep ort_Incubators_ECA.pdf

Eisenhardt, K. M. 1989. Building Theories from Case Study Research. Academy of Management Review, 14(4): 532-550. https://doi.org/10.5465/amr.1989.4308385

Gunter, F. 2012. A Simple Model of Entrepreneurship for Principles of Economics Courses. The Journal of Economic Education, 43(4): 386-396.

https://doi.org/10.1080/00220485.2012.714314

Hausberg, J. P., \& Korreck, S. 2018. Business Incubators and Accelerators: A Co-Citation Analysis-Based, Systematic Literature Review. Journal of Technology Transfer.

https://doi.org/10.1007/s10961-018-9651-y

Irshad, H. 2014. Business Incubation In Canada: Literature Review \& List Of Business Incubators In Alberta and Canada. Edmonton, Canada: Rural Development Division, Alberta Agriculture and Rural Development. http://cge.schulich.yorku.ca/wpcontent/uploads/2016/09/business-incubators-.pdf

Isabelle, D. 2013. Key Factors Affecting a Technology Entrepreneur's Choice of Incubator or Accelerator. Technology Innovation Management Review, 3(2): 16-22. http://doi.org/10.22215/timreview/656

Jakobsen, B., Tanev, S., \& Jensen, S. 2017. The Value of Business Incubation Services for the Growth of Early-Stage Startups. Proceedings of the ISPIM Innovation Forum: Fostering Innovation Ecosystems, March 19-22, 2017, Toronto, Canada. 


\section{Is Joining a Business Incubator or Accelerator Always a Good Thing?}

\section{Kristina Lukosiute, Søren Jensen, and Stoyan Tanev}

Mas-Verdú, F., Ribeiro-Soriano, D., \& Roig-Tierno, N. 2015. Firm Survival: The Role of Incubators and Business Characteristics. Journal of Business Research, 68(4): 793-796.

https://doi.org/10.1016/j.jbusres.2014.11.030

Mcadam, M., \& Marlow, S. 2007. Building Futures or Stealing Secrets? Entrepreneurial Cooperation and Conflict within Business Incubators. International Small Business Journal, 25(4): 361-382. https://doi.org/10.1177/0266242607078563

Maurya, A. 2012. Running Lean: Iterate from Plan A to a Plan That Works. Sebastopol, CA: O’Reilly.

Mian, S., Lamine, W., \& Fayolle, A. 2016. Technology Business Incubation: An Overview of the State of Knowledge. Technovation, 50-51: 1-12.

https://doi.org/10.1016/j.technovation.2016.02.005

Miller, P., \& Bound, K. 2011. The Startup Factories: The Rise of Accelerator Programmes to Support New Technology Ventures. London: Nesta.

http://www.eban.org/wp-content/uploads/2014/09/14.-

StartupFactories-The-Rise-of-Accelerator-Programmes.pdf

Rijnsoever, F. J., Weele, M. A., \& Eveleens, C. P. 2016. Network Brokers or Hit Makers? Analyzing the Influence of Incubation on Start-Up Investments. International Entrepreneurship and Management Journal, 13(2): 605-629.

https://doi.org/10.1007/s11365-016-0416-5

Sá, C., \& Lee, H. 2012. Science, Business, and Innovation: Understanding Networks in Technology-Based Incubators. $R \& D$ Management, 42(3): 243-253.

https://doi.org/10.1111/j.1467-9310.2012.00681.x

Yu, S. 2015. How Do Accelerators Impact the Performance of HighTechnology Ventures? Available at:

https://dx.doi.org/10.2139/ssrn.2503510

Citation: Lukosiute, K., Jensen, S., \& Tanev, S. 2019. Is

Joining a Business Incubator or Accelerator Always a

(cc) BY

Good Thing? Technology Innovation Management

Review, 9(7): 5-15.

http://doi.org/10.22215/timreview/1251

Keywords: incubator, accelerator, start-up, new venture, disadvantages, Denmark, Canada, Lithuania 


\section{Academic Affiliations and Funding Acknowledgements}
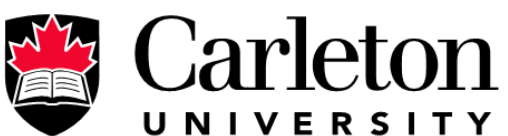

U N I V E R S I T Y

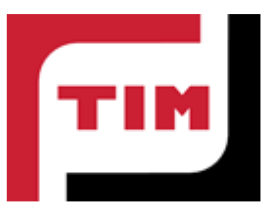

Technology Innovation Management (TIM; timprogram.ca) is an international master's level program at Carleton University in Ottawa, Canada. It leads to a Master of Applied Science (M.A.Sc.) degree, a Master of Engineering (M.Eng.) degree, or a Master of Entrepreneurship (M.Ent.) degree. The objective of this program is to train aspiring entrepreneurs on creating wealth at the early stages of company or opportunity lifecycles.

- The TIM Review is published in association with and receives partial funding from the TIM program. 